Gut, 1966, 7, 298

\title{
European Pancreatic Club
}

\author{
Twenty-five scientists and clinicians from Europe met at the Ciba Foundation, 41 Portland Place, \\ London W.1 on 9 and 10 December 1965 to form the European Pancreatic Club. \\ Dr. H. T. Howat was Chairman at the scientific sessions, at which discussion centred around the \\ theme of 'pancreatic enzymes'.
}

EFFECTS OF LYSINE DEFICIENCY ON HYDROLASES IN THE PANCREAS AND SMALL INTESTINE OF YOUNG RATS

J. CHRIstophe (Laboratoire de Chimie Biologique et de la Nutrition, Université Libre de Bruxelles, Belgium). The ingestion of gluten, as sole dietary protein, results in severe lysine deficiency and subacute threonine deficiency in young rats. These animals stop growing forthwith. After three weeks changes are found in the exocrine pancreas. The mitotic index is low. The apex of acinar cells shrinks, and the cell contains on an average $38 \%$ less protein and $19 \%$ less RNA-P. The decrease in protein content mostly affects hydrolases, amylase, chymotrypsinogen, trypsinogens, lipase, and procarboxypeptidase B, and more especially the first three of these proteins. A relative increase in the secretion of pancreatic enzymes is noted in the small intestine.

When deficient rats are allowed to recover on a complete diet, spectacular recovery is observed after three days. The mitotic index of acinar cells increases seventeenfold and the apex of the cell reverts to normal size, being refilled with hydrolases. By following the kinetics of adaptative changes in the pancreas more closely, in lysine deficiency as well as during recovery from lysine deficiency, it becomes obvious that major modifications in enzyme concentration develop within 24 hours. The velocity and magnitude of the variations in amylase and chymotrypsinogen are especially striking.

ADAPTATION OF THE ENZYMES OF EXOCRINE PANCREAS IN RESPONSE TO ALIMENTARY AND HORMONAL STIMULI

A. BEN ABDELJLIL (Institut de Chimie Biologique, Faculté des Sciences, Marseilles, France). Since the pancreas produces at least one enzyme hydrolysing each class of alimentary foodstuffs (several proteolytic enzymes for proteins, an amylase for polysaccharides, a lipase for triglycerides, and two nucleases for nucleic acids), it might be expected that a change in the relative proportions of these dietary ingredients would induce adaptation, leading to increase in the enzymes specifically involved in the hydrolysis of the main component of the diet.

A starch-rich diet (diet $G$ ) increases about threefold she level of amylase in rat pancreas and pancreatic juice, whereas a casein-rich diet (diet P) increases the level of proteolytic enzymes such as chymotrypsinogen, trypsinogen, and procarboxypeptidase B. By contrast, a lipid-rich diet has no effect on lipase. Starch can be re- placed in diet $\mathrm{G}$ by an equivalent amount of dextrose and casein in diet $\mathbf{P}$ by an amino-acid mixture. This suggests that the adaptation process is determined by digestion products, probably after their entry into blood. When the diet remains unchanged, the enzyme levels remain constant (steady state). Immediately after changing the diet the levels vary and reach exponentially their new values in three to five days.

In order to find out the mechanism by which the pancreas receives the necessary information which leads to adaptation, experiments have been performed on alloxaninduced diabetic animals (pancreas D). In these animals, amylase levels are very low but return to normal after treatment with insulin. In contrast with what obtains for pancreatic amylase, the level of salivary amylase is largely independent of insulin and the composition of the diet.

ADAPTATION OF THE ENZYMES OF EXOCRINE PANCREAS IN TERMS OF BIOSYNTHESIS

P. DESNUELLE (Institut de Chimie Biologique, Faculté des Sciences, Marseilles, France). It can be proved by purification procedures that the adaptation of pancreatic amylase and chymotrypsinogen involves a change in the number of enzyme molecules present at a given time in pancreas and pancreatic juice, rather than a change in the activity of these molecules. Since the number of enzyme molecules is controlled by a dynamic equilibrium between biosynthesis and loss (degradation (turnover) and discharge) it is interesting to see which factor is actually affected during adaptation.

Experiments using ${ }^{14} \mathrm{C}$ - labelled valine show that for the same incorporation into total proteins, pancreas $\mathbf{G}$ incorporates five or six times more radioactivity into amylase than pancreas $\mathbf{P}$ or $\mathbf{D}$. By contrast, pancreas $\mathbf{P}$ incorporates 2.5 times more radioactivity into chymotrypsinogen than pancreas $G$. These results suggest that the rates of enzyme biosynthesis are affected by adaptation. They are fully confirmed by other experiments carried out in vivo with pancreatic slices during which the specific radioactivity of the intrapancreatic precursor is measured and, consequently, the rates themselves are calculated. Pancreas $G$ appears to synthesize amylase eight or nine times more rapidly than pancreas $\mathbf{P}$, whereas pancreas $\mathbf{P}$ synthesizes chymotrypsinogen twice as rapidly as pancreas $\mathbf{G}$.

It can also be estimated that one acinarcellof pancreas 
$G$ is able, for instance, to synthesize $2.4 \times 10^{6}$ amylase and $5 \cdot 2 \times 10^{5}$ chymotrypsinogen molecules per minute. This apparently high production is in keeping with recent reports of the time required for the complete synthesis of one protein molecule by isolated reticulocytes or pancreatic slices.

\section{AMYLASE ACTIVITY-COMPARISON OF METHODS}

KLAUS HEINKEL (Bad Windsheim, Germany). Amylase is a very stable enzyme. While there are great differences between the action of the alpha- and beta-amylases of plants, no authenticated isolation of isoenzymes of the alpha-amylase in animals has yet been achieved. The classical separation of the alpha- and beta-amylases emphasizes the importance of the methods used to estimate amylase. While alpha-amylase in a few steps splits the starch molecules to achrodextrins, beta-amylse releases molecules of maltose from the ends of the chain. Additional differences exist in the residues after the action of amylase on starch.

Starches are not of uniform chemical composition. The particular enzyme actions of alpha- and beta-amylases and the differences in the starch preparations allow us to apply various techniques to measure amlyase activity. In principle, the effect of amylase can be determined by its influence on the viscosity of a starch paste, on the disappearance of the opaqueness of a starch suspension, on the splitting of starch measured by the remaining iodine-stainable starch, as well as by determination of newly formed reducing groups. Modifications of the techniques are obtained by changing the $p \mathrm{H}$, the time of incubation, and by varying the proportions of different reagents.

With normal human serum our results show no reliable correlation between the activities of amylase measured by different methods. In urine there is a relative correlation. In the diagnosis of pancreatic disease the differences between the methods used are of little consequence, since in pathological conditions, and particularly in acute pancreatitis, great increases in activity are obtained.

There is no basis on which to define international units of amylase activity, because although the amount of the substrate may be known, its molecular weight is not. Also unknown is the molecular weight of the newly formed compound. It is speculative whether a molecular weight, of for instance $\mathbf{3 4 2}$ for maltose as the theoretical end product, can be assumed to be correct. Amylase activity is appropriately defined in our present state of knowledge in milligrams or grams of split starch for a defined incubation time and temperature. The various methods cannot be compared one with another, so that a standardization of units does not help to provide comparable results. This is as true for determinations which have been made very sensitive as for others in which a large quantity of enzyme and substrate are used.

\section{AMYLASE ISOENZYMES}

A. DELCOURT AND P. WeTtendorfF (Brussels, Belgium). For some 15 years electrophoretic separation of the isoenzymes of amylase has been the subject of several studies, which have been contradictory for several reasons. The authors have been concerned with different techniques and have used various methods to estimate amylase. Thus in 1953 we described in mouse serum two amylase fractions which migrated in association with the beta $I$ fractions and alpha globulins. In 1954 Baker showed that in man there was evidence of one band only, corresponding to the gamma globulin fraction. We had abandoned this question because our method of determining amylase by the Somogyi saccharogenic method lacked sensitivity.

More recently McGeachin's work has revived interest in this question. Using a very sensitive iodometric method for amylase determination and paper electrophoresis, the author has shown the existence in human serum of two dominant active fractions which migrate with the albumin and gamma globulin. The latter corresponds, according to the author, to salivary and pancreatic amylase. These points were confirmed by Dreiling who applied this study to pancreatic disease in man.

We have taken up this line of research, using the technique described by McGeachin, and studying at various electrophoretic bands the kinetics of the reaction. Further, we have looked for areas of hydrolysis on gelose-starch plates in contact with electrophoretic bands, the starch being defined by iodine solution. The experiments were carried out with varying incubation conditions both of temperature and duration.

1 There is obvious discoloration of the iodine-starch complex at the level of the albumin and gamma globulin fractions in the electrophoretic bands.

2 The 'albumin' band discoloration does not correspond to any enzyme activity but is attributed to an artefact, due to the action of albumin on the iodine-starch complex. 3 Amylase activity is confined to the 'gamma globulin' fraction. Further, at that level the amylase activity of both salivary and pancreatic origin is found.

These conclusions have been recently confirmed by Berk and Wilding.

PROTEOLYTIC ENZYMES: TRYPSIN AND CHYMOTRYPSIN

W. RICK (I. Medizinische Universitätsklinik, Frankfurt am Main, Germany). For specific assays of trypsin and chymotrypsin we used N-benzoyl -L-arginin-ethyl ester (BAEE) and L-tyrosin ethyl ester (TEE) respectively. For trypsin in human duodenal juice we found a $K_{M}$

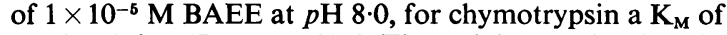
$1 \times 6 \cdot 10^{-3} \mathrm{M}$ TEE at $p \mathrm{H} 7 \cdot 0$. The activity can be given in international units per $\mathrm{ml}$. (i.u./ml). (1 i.u. is the amount of enzyme which under defined, optimal conditions will catalyse the conversion of $1 \mu \mathrm{Mol}$ of substrate per minute at $25^{\circ}$ : Report, Enzyme Commission, International Union of Biochemistry). Since different authors use different substrates, results are not comparable; it is therefore suggested that crystalline enzymes should be used as reference substances similar to the work of Borgström, Haverback and Ammann. The specific activities of trypsin from different species differ only slightly from each other: cattle, pigs, sheep $=95,91,100$.

In pancreatic secretion obtained during operations or from patients with a pancreatic fistula no active proteases, only zymogens were found. In duodenal juice the enzymes 
were completely activated. Up to eight hours after collection of the samples the activities of proteases showed no decrease. For quantitative sampling of duodenal contents we used the three-lumen tube (Bartelheimer) by which contamination with gastric juice and loss of duodenal juice are prevented by balloons. The amount of enzyme secreted per minute is then given as the enzyme secretion rate, analogous to hormone secretion rates of endocrine glands. In 25 healthy subjects a clear increase in the enzyme secreted was caused by secretin. The highest rates were observed after giving pancreozymin, so that it is sound to use these values as a criterion of exocrine function of the pancreas. The average secretion rate of trypsin was $0.73 \mathrm{mg} . / \mathrm{min}$. (range: $\overrightarrow{\mathrm{x}}-2 \mathrm{~S} . \mathrm{D} .=0.38$ mg./min. $\overline{\mathrm{x}}+2 \mathrm{~S} . \mathrm{D} .=1.42 \mathrm{mg} . / \mathrm{min}$.$) , and that of$ chymotrypsin $3.0 \mathrm{mg}$./min. (range $1.22-7.6 \mathrm{mg}$. $/ \mathrm{min}$.). In a group of patients suffering from chronic pancreatitis the secretion of the proteases was less than the secretion of amylase while a second group showed a uniform decrease of all pancreatic enzymes. In patients with calcifying pancreatitis only traces of enzymes were found.

Reports on finding active trypsin in blood may be ascribed to the use of unsuitable or non-specific substrates. The inhibiting capacity of serum (alpha $a_{1}$-antitrypsin, inter-alpha-antitrypsin, alpha ${ }_{2}$-antiplasmin) is sufficient for about $1 \mathrm{mg}$. trypsin to be inhibited by $1 \mathrm{ml}$. of serum. Recently, an antichymotrypsin has also been described.

PEPTIDASES: PROBLEMS IN CLINICAL PANCREATIC RESEARCH

H. wợRST (Medizinische Klinik der Universität Erlangen, Nürnberg, Germany). The classification of exopeptidases is based on the realization that specificity depends not so much upon the chain length of the substrate, but upon the nature of the terminal amino-acids and their ionic groups. Exopeptidases hydrolyse peptide-bonds adjacent to terminal amino or terminal carboxyl groups. Dipeptidases exclusively split dipeptides having a free amino and a free carboxyl group. They do not attack tripeptides, acyldipeptides, and dipeptide amides. Carboxypeptidases (COP-A and COP-B) hydrolyze peptide bonds adjacent to terminal free carboxyl groups. Aminopeptidases require a terminal amino group. The best known enzymes are leucinaminopeptidase (LAP) and aminotripeptidase with the substrate diglycyl-glycin. LAP also splits leucine-dipeptides.

Most peptidases are metallo-enzymes. The metallic ion is loosely or tightly bound to the enzyme protein; metal poisons inhibit their activity. Apparently the mechnism of metal activation is not uniform; some peptidases, like $\mathrm{Co}^{++}$-activated GG-dipeptidase, have full activity immediately on addition of metal ions, while others like prolidase show a 'slow reaction' and require a pre-incubation period with the effector added for several hours before starting the reaction.

Our knowledge of the optimal specific substrates of the most important peptidase is still incomplete, for instance, the chromogenic substrates of COP. Several methods of assessing enzyme activity are available. Alcoholic titration requires relatively large amounts of expensive substrates and is inadequate for the study of the initial rate of hydrolysis. The reversal-point on titration with the indicator is not sharp. A similar procedure and interpretation is the rarely used formol titration. The colorimetric assay with ninhydrine is not absolutely specific, because ammonium ions and amides give positive reactions. We have used in estimating COP the chromogenic method as modified for the examination of pancreatic function by Rick, Schön, Rässler, and Henning. Both carboxypeptidases are secreted by the pancreas as the zymogens, proCOP-A and pro-COP-B. Both active enzymes are $\mathrm{Zn}$ proteins and have a similar molecular weight. ProCOP-A has a molecular weight of 96,000 and pro-COP-B of 57,400 . There are also differences in extinction coefficient, and in the composition and the terminal sequence of amino-acids.

After oral stimulation of the pancreas with $300 \mathrm{ml}$. of broth COP activity increases on average to twice the basal secretion and after pancreozymin the mean value is again doubled, but the enzymatic response is more transient than the response to broth. For COP-activity, as for the other enzymes we distinguish between two forms of disturbed enzyme secretion. The first abnormality consists of decreased enzyme activity after oral stimulation only; the second after oral and parenteral stimulation. Of 163 patients examined, 23 showed the first form and 18 the second form of pancreatic insufficiency. We consider insufficiency after oral stimulation alone 'functional' and insufficiency after oral and parenteral stimulus 'organic'. In some patients with digestive disturbances the initially normal enzyme activity in duodenal juice has rapidly declined. We have therefore studied spontaneous inactivation of enzymes in vitro under constant conditions. COP is more resistant to inactivation in an alkaline lipase in an acid medium. At $22^{\circ} \mathrm{C}$. and at $p \mathrm{H} 7.8 \mathrm{COP}$ has a higher activity than initially, presumably due to tryptic activation being completed after the initial determination.

\section{THE ACTIVATION OF PROTEOLYTIC PROENZYMES}

W. NAGEL (Physiologisch Chemisches Institut der Universität, Heidelberg, Germany). The new developments in the field of the molecular morphology of trypsinogens and chymotrypsinogens, and the mechanisms of the activation of proteolytic proenzymes were reviewed.

Zymogen activation is influenced by various inhibitors. Among inhibitors of zymogen activation are certain amino acids, e.g., $\epsilon$-amino-caproic acid, and particularly effective is p-amino-methyl-benzoic acid (PAMBA) as well as $\alpha$-keto acids (e.g., p-hydroxyphenyl pyruvic acid) and guanidino compounds. These substances inhibit the activation of trypsinogen both by enteropeptidase and auto-catalytically and the activation of chymotrypsinogen by trypsin. The proteolytic and esterolytic activities of trypsin and $\alpha$-chymotrypsin are only very slightly if at all inhibited. The quantitative analysis of enzyme-proenzyme-mixtures is reported briefly.

In recent years it has been possible to extract from the pancreas of various species a series of proteolytic enzymes in a more or less pure state. The zymogens of these proteolytic activites are only partly known. The elastase first described by Balo and Banga is formed as proelastase 
in pancreatic acinar cells. This proenzyme is activated by trypsin. A 'protaminase' and a proteolytic enzyme found with it (Weil and Telka), as well as the 'esteroproteolytic enzyme of Gjessing and others are formed from their precursors by trypsin. Recently there has been isolated from pig pancreas a new enzyme of the chymotrypsin group, chymotrypsin $\mathrm{C}$ and its zymogen, chymotrypsinogen C (Folk and Schirmer). Chymotrypsinogen $\mathrm{C}$ is also activated by trypsin. At present it is not known whether corresponding zymogens exist for a number of other proteolytic activities found in pancreatic extracts and how these are activated into active enzymes. Among such enzymes are proteinase I and II from pig pancreas (Uriel and Avrameas) and a proteinase discovered by Rick in homogenates of rat and pig pancreas.

Personal experiments are concerned with pathological biochemistry of experimental pancreatitis. Research has been carried out on the activation of trypsinogen in the complex medium of a pancreatic homogenate. The optimum activation of trypsinogen in rat pancreatic homogenates took place in the $p \mathrm{H}$ range between $4 \cdot 2$ and $4 \cdot 5$. Above $p H 5.8$ no activation could be demonstrated during an incubation time of six hours. Addition of Kunitz inhibitor (Trasylol, Inipol) completely stopped the appearance of active trypsin, as did the addition of benzamidine to the homogenates. However, even when the formation of trypsin in rat pancreatic homogenates is blocked by various inhibitors, during incubation (maximum at $p H \mathbf{H} \cdot 2$ ) a proteolytic enzyme is activated; the process of activation must therefore be completely independent of trypsin. The $p \mathrm{H}$ optimum of this newly activated enzyme lies between $7 \cdot 5$ and 8.0 . This enzyme has been partially purified and some of its characteristics delineated. Its identification with one of the abovementioned proteinases remains possible.

It is clear that the spectrum of pancreatic proteinases is much broader than was originally thought. The consequences of this fact in the pathogenesis of acute pancreatitis was discussed.

\section{PANCREATIC RIBONUCLEASES}

J. J. BEINTEMA AND M. GRUBER (Biochemisch Laboratorium, Rijksuniversiteit, Groningen, The Netherlands). The relation between the structure and the enzymatic activity of bovine pancreatic ribonuclease has been studied for many years. However, much less work on pancreatic ribonucleases from other mammals has been done. The only available information is about the structure of ovine and porcine ribonuclease (Anfinsen et al., 1959; Katz et al., 1959). Work on horse ribonuclease has just started in our laboratory. Human, cat, and rabbit pancreas do not contain significant amounts of ribonuclease activity withstanding $0.25 \mathrm{~N}$ sulphuric acid.

In our laboratory rat pancreatic ribonuclease has been studied for some time. The enzyme is isolated in a way similar to that for bovine pancreatic RNase. Final purification is achieved by chromatography on Amberlite IRC-50 or on CM-cellulose. Rat RNase always appears in a single peak, on Amberlite a little later, on CMcellulose much later than bovine RNase-A. At $p \mathrm{H} 7.5$ the specific activity of the rat enzyme on RNA and cyclic $2^{\prime}, 3^{\prime}$-CMP is about half, but on cyclic $2^{\prime}, 3^{\prime}$-UMP about twice the activity of bovine RNase. Rat RNase contains no Trp. The enzyme contains more Pro, Gly, Ileu, Leu, Lys, His, and Arg, and less Ala, Val, and Tyr than bovine RNase. Bovine RNase contains three normal and three abnormal titrating tyrosines, rat RNase one normal and three abnormal.

Performic acid-oxidized rat and bovine RNases are studied by peptide mapping after digestion by trypsin and chymotrypsin (Katz et al., 1959). The 'maps' appear quite different. The peptides arising after tryptic and chymotryptic digestion of the performic acid-oxidized rat RNase, are separated and purified by column chromatography. The sum of the amino-acid analyses of the tryptic peptides agrees with the amino-acid analysis of undigested RNase. It is possible to put the tryptic peptides in a correct sequence. The $\mathrm{N}$-terminal amino-acids of the peptides are being determined by the Dansyl method (Gray and Hartley, 1963) and the sequence of the rest of the amino-acids by Edman degradation.

The N-terminal part of rat RBase is three amino-acids longer than that of bovine RNase. The position of about $30 \%$ of the amino-acids is different in rat and bovine RNase. Those parts of the molecule, which are important for the enzymatic activity (e.g., Richards, 1964), and the hydrophobic parts are very similar in both RNases, but other parts differ greatly.

REPORT ON DEBOXYRISONUCLEASE ACTIVITY IN SERUM

K. Roos (read by R. GAMkLou), Surgical Clinic I, Sahlgrenska Sjukhuset, Göteborg, Sweden). The serum activity of desoxyribonuclease I (DNA-ase I) was determined in 108 patients with or without pancreatic disease. In grave, and especially lethal, cases of acute pancreatitis considerably higher values of DNA-ase I activity in serum are obtained than in mild cases. Since this also applies to the first test performed after admission, the method can help in forming a prognostic opinion, which determination of amylase activity cannot, since the increase in amylase activity does not depend upon the severity of the pancreatitis. An increased DNA-ase I activity persisted for one to three weeks in the severe cases of pancreatitis, and thus can be of value in diagnosis even after the amylase values have returned to normal.

ESTIMATION OF LIPASE AND PROTEOLYTIC ENZYMES IN DUODENAL JUICE

HENRI SARLES AND CATHERINE FIGARELla (Hôpital Sainte Marguerite, Marseilles, France). In order to obtain accurate assays of lipase and proteolytic enzymes in duodenal juice, one must apply the laws of chemical kinetics governing the mechanism of all enzymatic reactions, and consider the effects of other components of the duodenal juice on the specific pancreatic enzymes being measured.

Principles An enzyme catalyses a specific chemical reaction. Because an enzyme is not usually found in a pure state, it can be measured quantitatively and qualitatively only by the determination of the rate of a specific 
reaction catalysed by the specific enzyme and by the measurement of the amount of end product produced by this reaction. The rules of chemical kinetics (zero order reaction) must be applied, and a specific substrate must be used.

Because duodenal juice is a complex mixture of biliary, pancreatic, and deuodenal secretions, the effects of these various components must be taken into account, especially the effects of bile salts and active trypsin. An important consideration is maintaining the stability of the enzymes during assay.

Assay of lipase The necessary substrate is a long-chain triglyceride insoluble in water. If the ester substrate is soluble in water, it is attacked not by the lipase, but by other pancreatic enzymes. We have used an emulsion of olive oil and arabic gum. A well-known problem we have encountered is the progressive activation and then inactivation of lipase caused by increasing concentrations of bile salts. Duodenal juice has a variable quantity of bile salts, but, with the addition of a fixed quantity of commercial bile salts $(40 \mathrm{mg}$. sodium taurocholate and
$40 \mathrm{mg}$. sodium glycocholate for $10 \mathrm{ml}$. emulsion), we have obtained maximum lipase activity in 48 out of 50 samples of duodenal juice tested. We apply these conditions to every assay. Our lipase assay is reproducible and proportional to the quantity of duodenal juice used.

Assay of trypsin and chymotrypsin In duodenal juice, these two proteolytic enzymes are in an active state. But it has been necessary to verify their total activity by varying the conditions of the assay by the addition of pure trypsin and calcium salts. Complete activation is reached, and trypsin and chymotrypsin can be measured directly against the specific substrates BAEE and ATEE.

There is a linear reaction between the quantity of enzyme and the quantity of duodenal juice, and we verified that bile salts have no inhibitory effect on trypsin and chymotrypsin before and during the assay.

Improved methods of assaying lipase and proteolytic enzymes in duodenal juice will not only be of great help in clinical diagnosis of disease, but also open the way for further experimental research on humans.

H.T.H. 